\title{
Transforming Growth Factor-Beta Produced by Non-small Cell Lung Cancer Cells Contributes to Lung Fibroblast Contractile Phenotype
}

\author{
NOBUHIRO KANAJI ${ }^{1}$, MASANAO YOKOHIRA ${ }^{2}$, NAOKI WATANABE ${ }^{1}$, \\ NORIMITSU KADOWAKI ${ }^{1}$ and SHUJI BANDOH ${ }^{1}$ \\ ${ }^{1}$ Department of Internal Medicine, Division of Hematology, Rheumatology and Respiratory Medicine, \\ Faculty of Medicine, Kagawa University, Kagawa, Japan; \\ ${ }^{2}$ Onco-Pathology, Department of Pathology and Host-Defense, \\ Faculty of Medicine, Kagawa University, Kagawa, Japan
}

\begin{abstract}
Background/Aim: Fibroblasts can alter the extracellular matrix (ECM), contributing to cancer progression by providing a scaffold for cancer cells. The influence of lung cancer cells (LCCs) on lung fibroblastmediated ECM alteration is not well understood. Materials and Methods: After incubation in serum-free medium, LCCor fibroblast-conditioned media were collected. The ECM alteration was assessed by collagen gel contraction assay. Results: Both LCC-conditioned medium and exogenous transforming growth factor (TGF)- $\beta 1$ increased collagen gel contraction by lung fibroblasts. TGF- $\beta 1$ was produced in LCC-conditioned media at approximately $2 \mathrm{ng} / \mathrm{ml}$. SB431542, a specific TGF- $\beta$ receptor kinase inhibitor, partially inhibited the collagen gel contraction that had been increased by LCCconditioned media. Lung fibroblast-conditioned medium stimulated TGF- $\beta 1$ production from LCCs, whereas LCCconditioned medium decreased fibroblast survival and $\alpha$-smooth muscle actin expression by fibroblasts. Conclusion: Interaction between LCCs and lung fibroblasts through TGF- $\beta$ signaling induces fibroblasts to assume the contractile phenotype and may contribute to cancer progression.
\end{abstract}

Cancer progression is significantly affected by its microenvironment (1). Although most host cells in the cancer microenvironment possess certain cancer-suppressing

Correspondence to: Dr. Nobuhiro Kanaji, Department of Internal Medicine, Division of Hematology, Rheumatology and Respiratory Medicine, Faculty of Medicine, Kagawa University, 1750-1 Ikenobe, Miki-cho, Kita-gun, Kagawa 761-0793, Japan. Tel: +81 878912145, Fax: +81 878912147, e-mail: kanaji@med.kagawa-u.ac.jp

Key Words: Lung cancer, fibroblast, collagen gel contraction, cancer-associated fibroblast, transforming growth factor. abilities, the microenvironment changes during malignancy eventually promote growth, invasion and metastasis (2). Fibroblasts are abundant in the cancer microenvironment (1). These fibroblasts are called cancer-associated fibroblasts (CAFs); they acquire myofibroblast-like characteristics, such as overexpression of $\alpha$-smooth muscle actin (SMA) and alteration of extracellular matrix (ECM) (3-5).

The collagen gel contraction assay assesses ECM changes or tissue remodeling in vitro. Enhanced collagen gel contraction by fibroblasts can stimulate cancer progression because cancer cells usually require the ECM as their "scaffold." Detaching from the appropriate ECM, cancer cells normally undergo apoptosis - i.e., anoikis (6).

Transforming growth factor (TGF)- $\beta$ is a multifunctional cytokine that induces tissue fibrosis and remodeling by inducing various ECM proteins, thus affecting fibroblast functions $(7,8)$. TGF- $\beta 1$ differentiates lung fibroblasts to myofibroblasts (9), and stimulates fibroblast-mediated collagen gel contraction (8). Accumulating TGF- $\beta$ in the cancer microenvironment may activate fibroblasts to become CAFs $(2,10)$.

Cross-talk between lung fibroblasts and lung cancer cells (LCCs) has a complex effect on cancer progression. To investigate the interactions between these two cell types, we prepared LCC- and lung fibroblast-derived culture media, and assessed myofibroblast-like phenotypes and survival of lung fibroblasts. We found that TGF- $\beta$ produced from LCCs increases lung fibroblast-conditioned collagen gel contraction, and this production is stimulated by lung fibroblasts.

\section{Materials and Methods}

Reagents. Rat-tail tendon collagen was purchased from BD Biosciences (Franklin Lakes, NJ, USA; \#354236). Recombinant human TGF- $\beta 1$, TGF- $\beta 2$, TGF- $\beta 3$, platelet-derived growth factor (PDGF)-AA and PDGF-BB were purchased from PeproTech (Rocky Hill, NJ, USA). A specific TGF- $\beta$ receptor kinase inhibitor, 

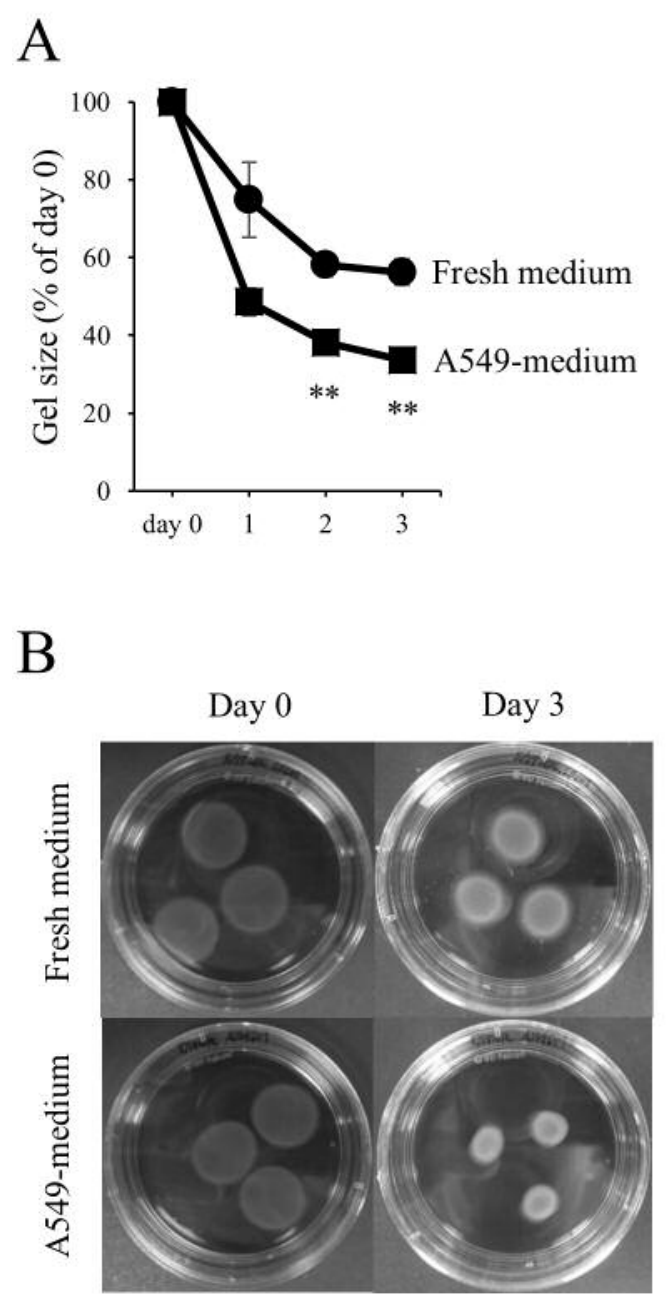

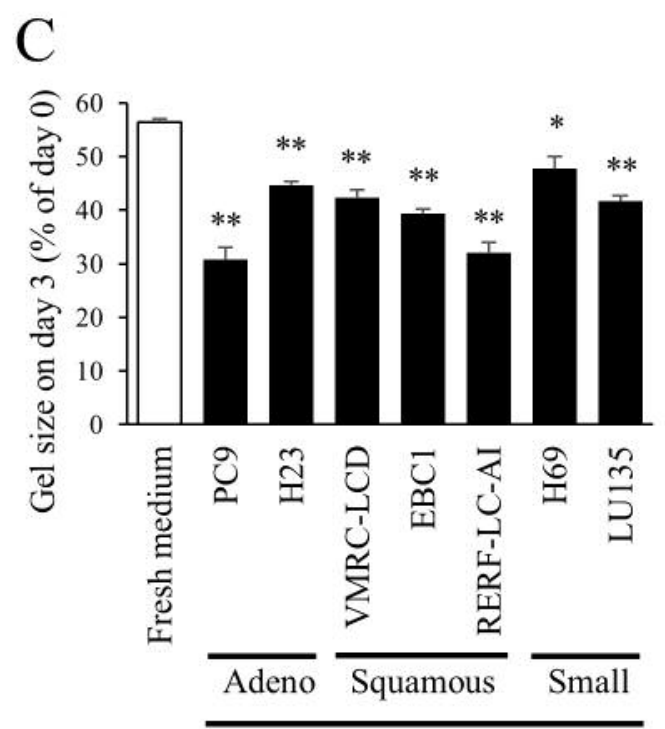

Lung cancer cell-mediated media

Figure 1. Effects of lung cancer cell-conditioned media on collagen gel contraction by HFL1 fibroblasts. (A) Gel contraction assay over time. HFL1 fibroblasts were cast into collagen gels (day 0) and cultured in fresh medium or A549-conditioned medium for 3 days. Data are shown as percentages of initial size, and are expressed as mean \pm SEM of 3 separate experiments. ${ }^{* *} p<0.01$ versus fresh medium. (B) Representative gels on day 3, cultured in A549-media. (C) Gel contraction by HFL1 in several lung cancer cell-conditioned media. Data on day 3 are shown as percentages of initial size. ${ }^{*} p<0.05$ or $* * p<0.01$ versus fresh medium.

SB431542, and antibodies against $\alpha$ - SMA and $\beta$-actin were purchased from Sigma-Aldrich (St. Louis, MO, USA), and PDGF receptor tyrosine kinase inhibitor III from Calbiochem (EMD Millipore, Darmstadt, Germany).

Cell culture and collection of cell-conditioned medium. Human fetal lung fibroblasts (HFL1, IMR-90 and MRC-5) were purchased from the American Type Culture Collection (Rockville, MD, USA). These cells were cultured with DMEM supplemented with 10\% FBS. Fibroblasts were used between the 16th and 20th passages. Human LCC lines (A549, PC9, H23, VMRC-LCD and HI1017 [adenocarcinomas]; EBC1 and RERF-LC-A1 [squamous-cell carcinomas]; H69 and LU135 [small-cell carcinomas]) were obtained from the Japan Cancer Research Bank (Tokyo, Japan). LCCs were cultured in RPMI-1640 supplemented with 10\% FBS. To collect LCC- or fibroblast-conditioned medium, at subconfluence, cells were rinsed with serum-free DMEM twice, and incubated with serum-free DMEM $\left(2 \mathrm{ml} / 10^{6}\right.$ cells $)$ for $48 \mathrm{~h}$. Medium was then collected and centrifuged; the supernatant was designated as LCC or fibroblast-conditioned medium (e.g., "A549medium," or "HFL1-medium"). Each cell-conditioned medium was prepared at least three times independently.

Collagen gel contraction assay. Collagen gel contraction assays were performed as described (8). Briefly, on day 0 , distilled water, $4 \times$ concentrated DMEM, and rat-tail tendon collagen were mixed, and cells were then added into the mixture so that the final concentration of collagen was $0.75 \mathrm{mg} / \mathrm{ml}, 1 \times \mathrm{DMEM}$ concentration, and final cell density was $1 \times 10^{5}$ cells $/ \mathrm{ml}$. Gels were placed into $60-\mathrm{mm}$ dishes that contained $5 \mathrm{ml}$ of DMEM without FBS, and maintained at $37^{\circ} \mathrm{C}$ in a humidified atmosphere of $5 \% \mathrm{CO}_{2}$. Gels were measured with a stereoscopic microscope with an image analyzer system (Olympus, Tokyo, Japan; SZX10 and DP21) on day 3. Gel size was expressed as percent of initial size on day 0 .

TGF- $\beta$ measurement by ELISA. TGF- $\beta$ concentration was measured by ELISA. Briefly, 96-well plates were coated with monoclonal anti-TGF- $\beta$ antibodies (R\&D Systems, Minneapolis, MN, USA; MAB240, MAB612, and MAB243 for TGF- $\beta 1$, TGF- $\beta 2$, and TGF$\beta 3$, respectively) overnight at $200 \mathrm{ng} / 100 \mu \mathrm{l}$ for each well. Next day, to activate latent TGF- $\beta$ in the culture medium, $500 \mu$ l medium was treated with $100 \mu \mathrm{l}$ of $1 \mathrm{~N} \mathrm{HCl}$ for $10 \mathrm{~min}$, then neutralized with

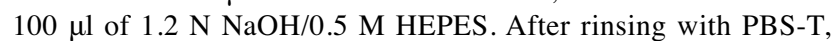
$100 \mu \mathrm{l}$ of standards (recombinant human TGF- $\beta$ ) and samples (culture media) were incubated for $2 \mathrm{~h}$ at $37^{\circ} \mathrm{C}$. After rinsing with 

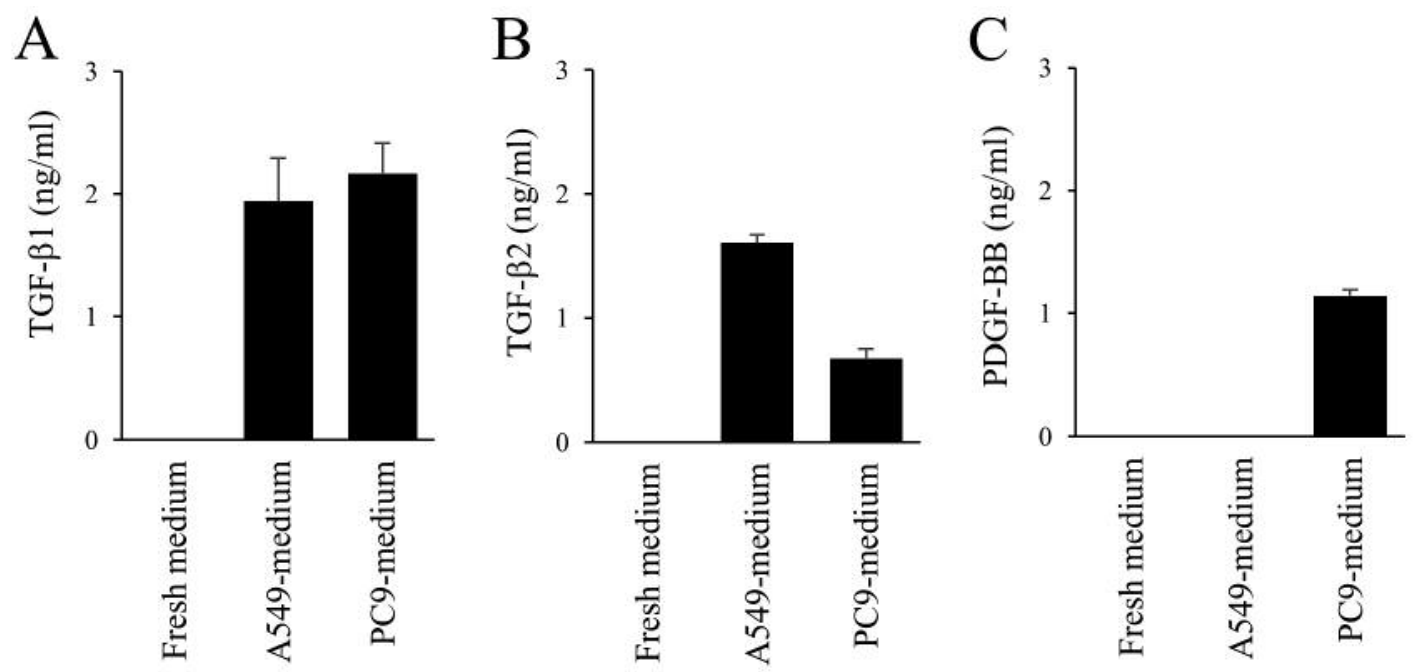

Figure 2. Growth factors production from lung cancer cells. Production of (A) TGF- $\beta 1,(B)$ TGF- $\beta 2$, and (C) PDGF-BB were measured by ELISA. Data are expressed as mean \pm SEM of 3 separate experiments. Lowest limit for detection was $0.31 \mathrm{ng} / \mathrm{ml}$.

A

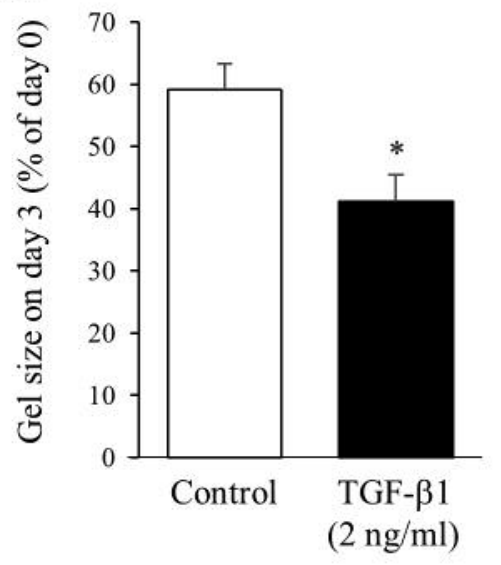

$\mathrm{B}$



Figure 3. Effects of exogenous growth factors on collagen gel contraction by HFL1 fibroblasts. (A) TGF- $\beta 1$ (2 ng/ml) or (B) PDGF-BB (1 or $10 \mathrm{ng} / \mathrm{ml})$ or PDGF-AA $(10 \mathrm{ng} / \mathrm{ml})$ was added into the fresh medium. On day 3, gel sizes were measured. Data are shown as percentages of initial size, and are expressed as mean $\pm S E M$ of 4 separate experiments. $* p<0.05$ versus fresh medium (control).

PBS-T, biotinylated antibodies (R\&D Systems, Minneapolis, MN, USA, BAF240, BAF302, and BAF243 for TGF- $\beta 1$, TGF- $\beta 2$, and TGF- $\beta 3$, respectively, $20 \mathrm{ng} / 100 \mu \mathrm{l}$ each well) were incubated for 1 $\mathrm{h}$ at $37^{\circ} \mathrm{C}$. After rinsing, streptavidin-HRP (Invitrogen, Carlsbad, CA, USA) was added and incubated for $1 \mathrm{~h}$. Reaction to $100 \mu \mathrm{l}$ of TMB liquid (Sigma-Aldrich, St. Louis, MO, USA) was stopped with $50 \mu \mathrm{l}$ of $1 \mathrm{M} \mathrm{H}_{2} \mathrm{SO}_{4}$. Optical densities (OD) at $450 \mathrm{~nm}$ were measured by a microplate reader (iMark ${ }^{\mathrm{TM}}$, Bio-Rad, Hercules, CA, USA). To calculate concentrations of acidified samples (total TGF- $\beta$ ), we multiplied by a dilution factor of 1.4 .

$P D G F-B B$ measurement by ELISA. PDGF-BB concentration was measured by ELISA. Briefly, 96-well plates were coated with monoclonal anti-PDGF-BB antibodies (AF-220-NA, R\&D Systems, Minneapolis, MN, USA) overnight at $200 \mathrm{ng} / 100 \mu \mathrm{l}$ each well. Next day, after rinsing with PBS-T, $100 \mu \mathrm{l}$ of standards (recombinant human PDGF-BB) and samples (culture media) were incubated for 

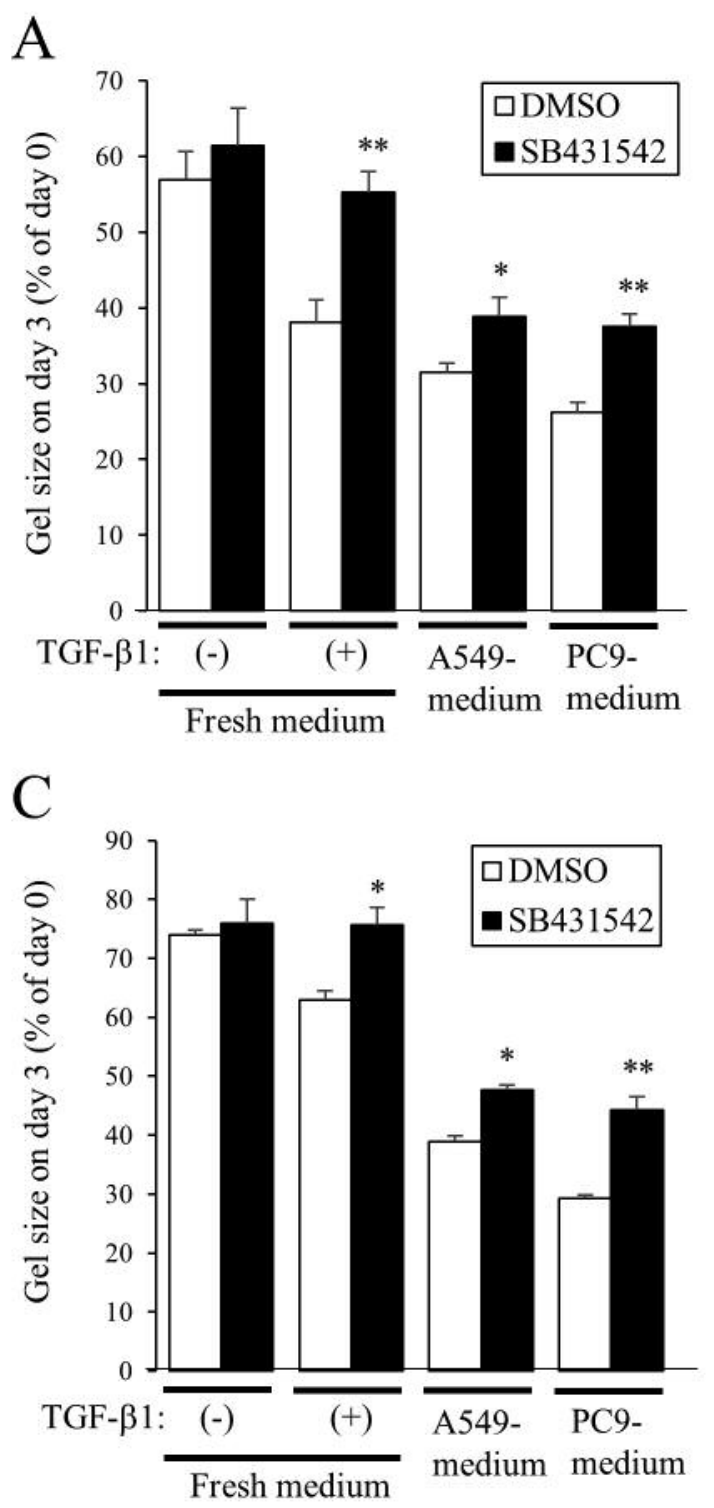

$2 \mathrm{~h}$ at $37^{\circ} \mathrm{C}$. After rinsing with PBS-T, biotinylated antibody (R\&D Systems, Minneapolis, MN, USA; BAF220, 20 ng/100 $\mu$ l each well) were added and incubated for $1 \mathrm{~h}$ at $37^{\circ} \mathrm{C}$. After rinsing, streptavidin-HRP (Invitrogen, Carlsbad, CA, USA) was added and incubated for $1 \mathrm{~h}$. Reaction with $100 \mu \mathrm{l}$ of TMB liquid (SigmaAldrich, St. Louis, MO, USA) was stopped with $50 \mu \mathrm{l}$ of $1 \mathrm{M}$ $\mathrm{H}_{2} \mathrm{SO}_{4}$. The OD at $450 \mathrm{~nm}$ was measured by a microplate reader (iMark $^{\mathrm{TM}}$, Bio-Rad, Hercules, CA, USA).

Immunoblots. Immunoblots were performed as previously described (11). Briefly, lung fibroblasts were lysed in lysis buffer $(35 \mathrm{mM}$ Tris [pH 7.4], $0.4 \mathrm{mM}$ EGTA, $10 \mathrm{mM} \mathrm{MgCl}_{2}$, and $0.1 \%$ Triton-100) supplemented with protease inhibitor cocktail (Sigma-Aldrich, St. Louis, MO, USA). Total cell lysate was homogenized in $2 \times$ sodium dodecyl sulfate (SDS) sample buffer, boiled, subjected to SDSpolyacrylamide (10\%) gel electrophoresis, and then transferred to a

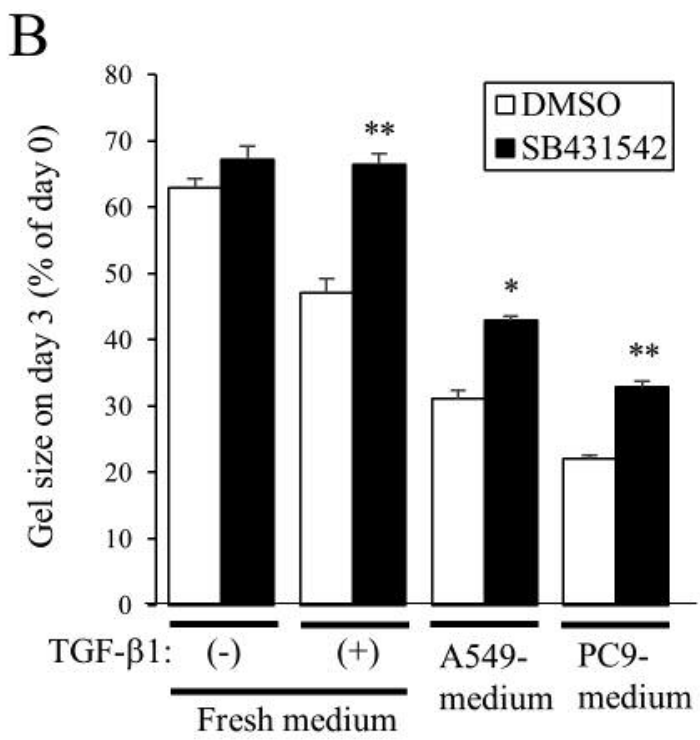

Figure 4. Effect of TGF- $\beta$ receptor kinase inhibitor on collagen gel contraction augmented by lung cancer cell-derived media. Gel contraction by three lung fibroblast cell lines - (A) HFL1, (B) MRC5, and (C) IMR90 - was assessed in the presence of TGF- $\beta 1(2 \mathrm{ng} / \mathrm{ml})$ or SB431542 $(10 \mu \mathrm{M})$. Data are shown as percentages of initial size, and are expressed as mean \pm SEM of 3 separate experiments. ${ }^{*} p<0.05$ or ${ }^{* *} p<0.01$, versus DMSO (control) under the same conditions.

polyvinylidene difluoride membrane. The membrane was blocked with $1 \%$ BSA and incubated with primary antibodies. After rinsing with PBS with $0.1 \%$ Tween-20, membrane was incubated with the appropriate HRP-conjugated secondary antibody. The intensity of positive signals was visualized by chemiluminescence (GE Healthcare, Buchinghamshire, UK), and imported by Image Reader LAS-1000 Plus (Fuji Photo Film Co. Ltd., Tokyo, Japan).

Lung fibroblast survival. Lung fibroblast survival (viability) was assessed by WST-1 assays. Briefly, cells were incubated in regular medium with $10 \%$ FBS and 10\% WST-1 reagent (Roche Applied Science, Mannheim, Germany). After incubation for 4 hours, 100 $\mu \mathrm{l}$ of samples were transferred to a 96-well plate and absorbance at $450 \mathrm{~nm}$ was measured by a microplate reader (iMark ${ }^{\mathrm{TM}}$, Bio-Rad, Hercules, CA, USA). All samples were assessed at least in triplicate. 


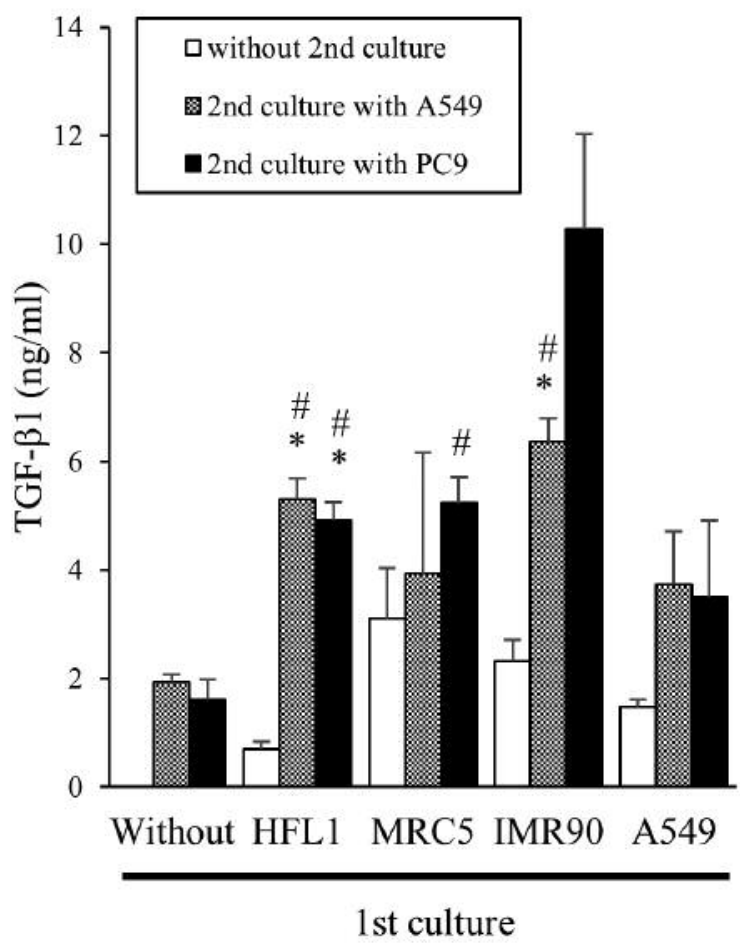

Figure 5. Stimulation of TGF- $\beta 1$ production from lung cancer cell by fibroblast-derived media. Fibroblasts were cultured for the 1st culture and their conditioned media were collected. At the 2nd culture, A549 and PC9 cells were cultured in fibroblast-conditioned media for 2 days, and their TGF- $\beta 1$ concentrations were measured. Data are expressed as mean $\pm S E M$ of 3 separate experiments. $* p<0.01$ versus control without 2 nd culture. ${ }^{\#} p<0.01$ versus control without 1 st culture.

Statistical analysis. Each experiment was repeated at least three times. Student's $t$-test was used to compare two-group data. $p<0.05$ was considered significant. All statistical analyses used EkuseruToukei 2015 (Social Survey Research Information, Tokyo, Japan).

\section{Results}

Culture media from LCC lines increased collagen gel contraction by lung fibroblasts. We first examined if LCC lines affected contractile ability of lung fibroblasts. A549 cells were cultured in serum-free conditions and the cellculture medium (A549-medium) was collected. When HFL1 fibroblasts were cultured in A549-medium, collagen gels contracted more robustly (Figure 1A, B). HFL1 fibroblasts cultured in conditioned media from other LCC lines also contracted collagen gels (Figure 1C). Different lung cancer histological types did not obviously differ in gel contractility.

Factors that were produced from LCCs affected collagen gel contractility. We next examined several LCC-produced factors that might affect collagen-gel contractility. TGF- $\beta 1$ was produced into the medium from both A549 cells (at $1.94 \pm 0.35 \mathrm{ng} / \mathrm{ml})$ and PC9 cells $(2.17 \pm 0.25 \mathrm{ng} / \mathrm{ml}$; Figure 2A). TGF- $\beta 2$ was also detected in A549-media (1.61 \pm 0.07 $\mathrm{ng} / \mathrm{ml})$ and PC9-media $(0.68 \pm 0.07 \mathrm{ng} / \mathrm{ml}$; Figure 2B). However, TGF- $\beta 3$ was not detected in either media (data not shown). PDGF-BB was detected only in PC9-medium $(1.14 \pm 0.05 \mathrm{ng} / \mathrm{ml}$; Figure 2C).

Exogenous TGF- $\beta 1(2 \mathrm{ng} / \mathrm{ml})$ increased collagen gel contraction by HFL1 (Figure 3A), as previously reported (8). At $1 \mathrm{ng} / \mathrm{ml}$, PDGF-BB had no effect on gel contraction, but did so at $10 \mathrm{ng} / \mathrm{ml}$ (Figure $3 \mathrm{~B}$ ).

Role of endogenous TGF- $\beta$ production on collagen gel contraction by fibroblasts. To confirm the effect of LCCproduced TGF- $\beta$ on collagen gel contraction by lung fibroblasts, we used SB431542, an inhibitor of TGF- $\beta$ receptor kinase activity. SB431542 strongly blocked the effect of exogenous TGF- $\beta 1$ on collagen gel contraction by HFL1 (Figure 4A). It also partially, but significantly, inhibited the increased contractility from A549- or PC9media (Figure 4A). The experiments using other lung fibroblasts, MRC-5 (Figure 4B) or IMR-90 (Figure 4C), showed similar results, whereas SB431542 completely blocked the effect of exogenous TGF- $\beta 1$ and partially blocked the increased effect by LCC-conditioned media.

Lung fibroblast-conditioned media increased TGF- $\beta$ production by LCCs. To investigate whether lung fibroblasts can affect TGF- $\beta 1$ production by LCCs, we next cultured lung fibroblasts in serum-free media for 2 days and collected the resulting conditioned media (HFL1-, MRC5-, or IMR90media). These fibroblast-conditioned media included TGF$\beta 1$ in varying concentrations (Figure 5, white bars). A549 and PC9 cells were cultured in these fibroblast-conditioned media for 2 days, and culture media were collected. Interestingly, LCCs produced more TGF- $\beta 1$ when cultured in fibroblast-conditioned media than in fresh medium (conventional LCC-conditioned media; cell-free conditions at 1 st culture shown in Figure 5).

LCC-conditioned media decrease fibroblast survival and do not induce fibroblast $\alpha-S M A$ expression. To investigate whether LCC-conditioned media induce $\alpha$-SMA expression from lung fibroblasts, total cell lysates were subjected to immunoblots. However, $\alpha$-SMA expression decreased after incubation in LCC-conditioned media (A549-, and PC9media), but increased when TGF- $\beta 1$ was added (Figure 6A). When HFL1 cells were cultured in LCC (A549- or PC9- media), HFL1 cell survival (viability) significantly decreased (Figure 6B). Similarly, survival of MRC5 and IMR90 cells was inhibited by LCC-conditioned media, but not fibroblastconditioned media (Figure 6C, D). 
A

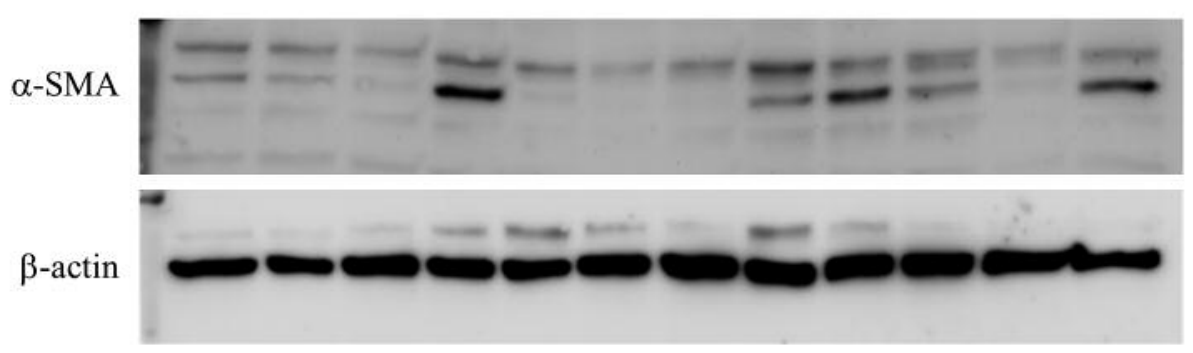

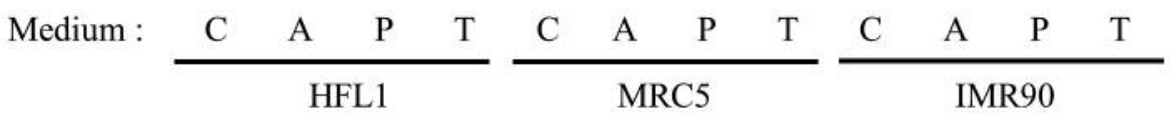

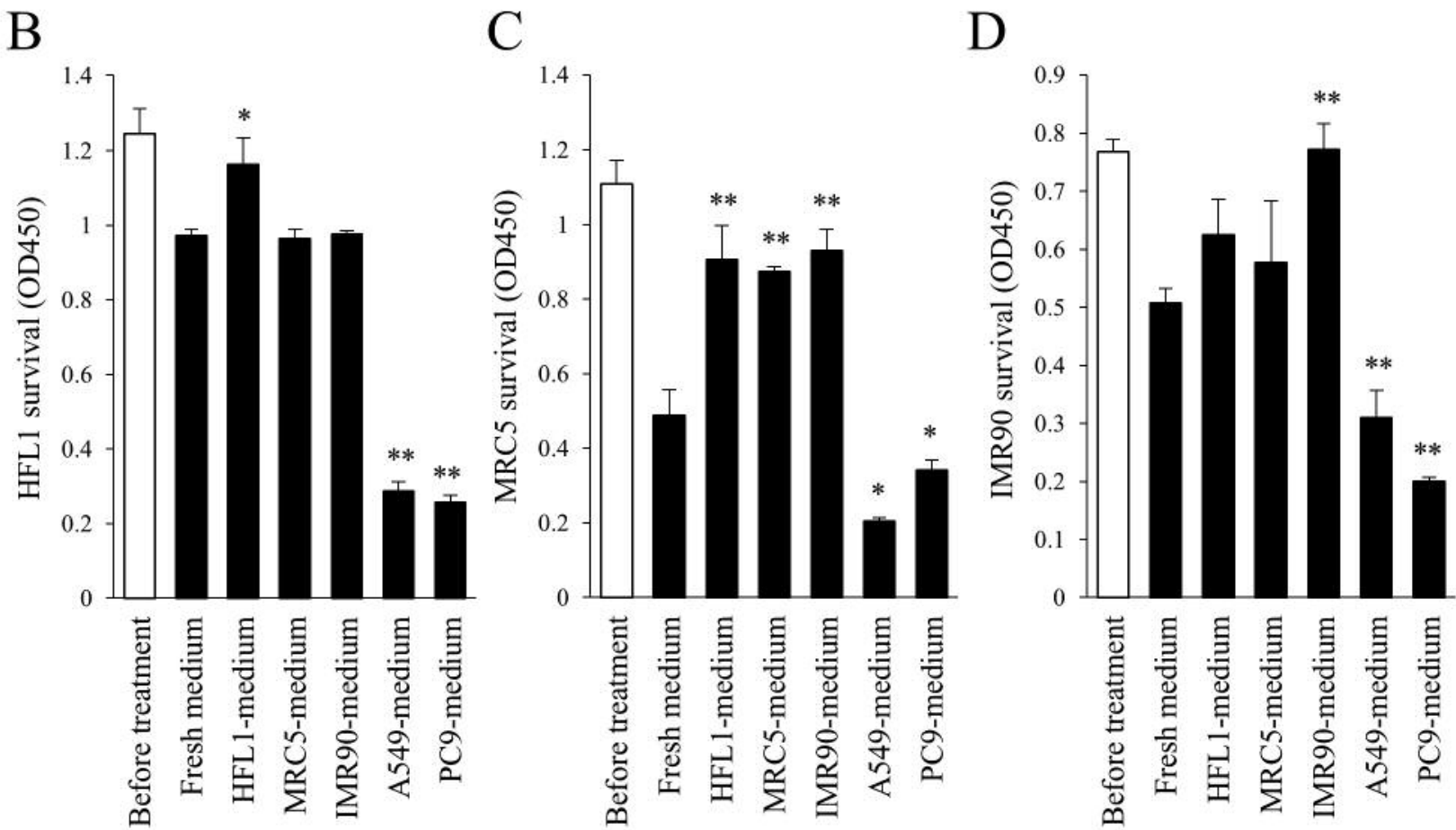

Figure 6. Effects of lung cancer cell-derived medium on $\alpha$-SMA expression and lung fibroblast survival. (A) $\alpha$-SMA expression. Lung fibroblasts were cultured in fresh medium, with or without TGF- $\beta 1(2 \mathrm{ng} / \mathrm{ml})$, or in lung cancer cell-derived media with $1 \%$ FBS for 2 days. Total cell lysates (5 $\mu \mathrm{g} / \mathrm{lane})$ were used for immunoblots that targeted $\alpha$-SMA or $\beta$-actin. C: control (fresh medium), A: A549-medium, P: PC9-medium, and T: added TGF-ß1. (B) HFL1, (C) MRC5, and (D) IMR90 survival. Fibroblasts were cultured in either fresh, serum-free medium, or fibroblast- or lung cancer cell-derived media for 5 days; cell survival (viability) was then assessed by WST-1. ${ }^{*} p<0.05$ or $* * p<0.01$ versus fresh medium.

\section{Discussion}

In the present study, we demonstrated that (a) LCCconditioned medium increased contraction of collagen gels by lung fibroblasts, at least partly through TGF- $\beta$ production; (b) lung fibroblast-conditioned medium stimulates TGF- $\beta$ production from LCCs; and (c) LCC-conditioned medium induces fibroblast death. These interactions between the two types of cells are summarized in Figure 7.

Majority of CAFs are derived from normal fibroblasts, and this transdifferentiation is often induced by cancer cell-derived cytokines such as TGF- $\beta$ (2). Interestingly in the present study, fibroblast-derived medium stimulated TGF- $\beta$ production from LCCs, which suggests that the contractile lung fibroblast 


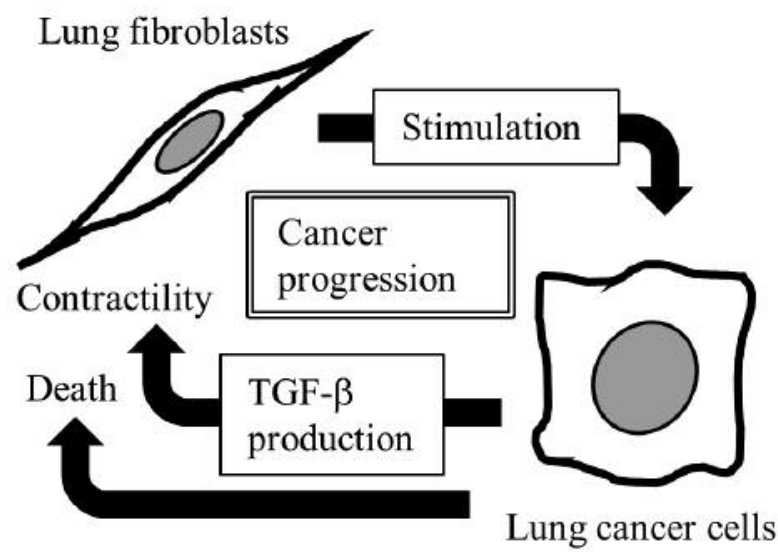

Figure 7. Schema of effects of lung cancer cells (LCCs) on the lung fibroblast contractile phenotype. TGF- $\beta$ produced by LCCs changed lung fibroblasts to a more contractile phenotype. Lung fibroblasts stimulated TGF- $\beta$ production by LCCs. LCCs induce death of fibroblasts. These interactions contribute to cancer progression.

phenotype is increased by these cells' interactions. The alteration of fibroblast characteristics in this situation is consistent with the concept of CAFs. CAFs reportedly enhance collagen gel contraction compared with normal fibroblasts (35). As CAFs obtained from resected cancer tissues might be affected by several cell types besides cancer cells (such as inflammatory cells and vascular endothelial cells), the present study used cell-free conditioned medium to rule out some interactions with non-cancer cells. The increase in collagen gel contraction by fibroblasts in LCC-conditioned medium suggests that the fibroblasts' change to the contractile phenotype is directly caused by LCCs, through TGF- $\beta$ expression. The contractile fibroblast phenotype is important for tissue repair/remodeling in wound closure and scar formation (12). As lung cancers, particularly adenocarcinomas, are often accompanied by fibrosis around cancer sites, the stimulatory effect of adenocarcinoma on the lung fibroblast contractile phenotype might be stronger than other lung cancer types. However, we saw no obvious differences in gel contractility among different lung cancer histologies.

Cancer is an "incurable wound" for fibroblasts. Tissue remodeling by contractile-phenotype fibroblasts at cancer sites provides the scaffold structure that supports cancer cell growth; alteration of ECM by fibroblasts also inhibits anoikis. On the other hand, $\alpha$-SMA expression was decreased by LCC-conditioned media. Therefore, we cannot conclude that changes in fibroblast phenotype induced by LCC-conditioned media are associated with CAFs. Similarly, LCC-conditioned media can reportedly inactivate myofibroblasts, as shown by decreased $\alpha$-SMA expression through cAMP-responsive element binding proteins (13). In addition, LCC-conditioned media decreased fibroblast survival (viability) in the current study. As TGF- $\beta 1$ is known to increase $\alpha$-SMA expression and to improve survival of lung fibroblasts (8), some factors other than TGF- $\beta$ in the LCC-conditioned media should affect multi-directional alteration of fibroblasts. Lung fibroblasts may be destined to die after LCCs utilized fibroblasts for own progression.

TGF- $\beta$ is probably not the only factor released by LCCs that affects contractile ability in fibroblasts. SB431542 only partially recovered collagen gel contractility that had been increased by LCC-conditioned media, which implies that some factors besides TGF- $\beta$ are in LCC-conditioned media. Although PDGF-BB is a candidate, its concentration in LCC-conditioned media was low and not enough to affect collagen gel contractions.

Another important finding of the current study was that lung fibroblasts stimulate TGF- $\beta$ production from LCCs. TGF- $\beta$ can induce phenotypic alteration of lung fibroblasts, and help induce epithelial-mesenchymal transition in lung cancer (7). TGF- $\beta$ signaling is also associated with confluence-dependent resistance to cisplatin (11). Thus, the interaction between LCCs and fibroblasts through TGF- $\beta$ signaling could synergistically contribute to cancer progression.

In summary, interaction via TGF- $\beta$ signaling between lung cancer cells and lung fibroblasts induces phenotypic contractile alteration of fibroblasts and may contribute to cancer progression.

\section{Acknowledgements}

The Authors thank Ms. Takimi Tamaki for her excellent experimental support of this work. The manuscript was edited by Edanz Editing, an English proofreading company.

\section{References}

1 Majety M, Pradel LP, Gies $\mathrm{M}$ and Ries $\mathrm{CH}$ : Fibroblasts influence survival and therapeutic response in a $3 \mathrm{D}$ co-culture model. PLoS One 10: e0127948, 2015.

2 Bremnes RM, Dønnem T, Al-Saad S, Al-Shibli K, Andersen S, Sirera R, Camps C, Marinez I and Busund LT: The role of tumor stroma in cancer progression and prognosis: emphasis on carcinoma-associated fibroblasts and non-small cell lung cancer. J Thorac Oncol 6: 209-217, 2011.

3 Navab R, Strumpf D, Bandarchi B, Zhu CQ, Pintilie M, Ramnarine VR, Ibrahimov E, Radulovich N, Leung L, Barczyk M, Panchal D, To C, Yun JJ, Der S, Shepherd FA, Jurisica I and Tsao MS: Prognostic gene-expression signature of carcinomaassociated fibroblasts in non-small cell lung cancer. Proc Natl Acad Sci USA 108: 7160-7165, 2011.

4 Horie M, Saito A, Mikami Y, Ohshima M, Morishita Y, Nakajima J, Kohyama T and Nagase T: Characterization of human lung cancer-associated fibroblasts in three-dimensional in vitro co-culture model. Biochem Biophys Res Commun 423: 158-163, 2012. 
5 Karvonen HM, Lehtonen ST, Sormunen RT, Lappi-Blanco E, Sköld CM and Kaarteenaho RL: Lung cancer-associated myofibroblasts reveal distinctive ultrastructure and function. J Thorac Oncol 9: 664-674, 2014.

6 Tan K, Goldstein D, Crowe P and Yang JL: Uncovering a key to the process of metastasis in human cancers: a review of critical regulators of anoikis. J Cancer Res Clin Oncol 139: 1795-1805, 2013.

7 Miyazono K: Transforming growth factor-beta signaling in epithelial-mesenchymal transition and progression of cancer. Proc Jpn Acad Ser B Phys Biol Sci 85: 314-323, 2009.

8 Kanaji N, Basma H, Nelson A, Farid M, Sato T, Nakanishi M, Wang X, Michalski J, Li Y, Gunji Y, Feghali-Bostwick C, Liu X and Rennard SI: Fibroblasts that resist cigarette smoke-induced senescence acquire profibrotic phenotypes. Am J Physiol Lung Cell Mol Physiol 307: L364-L373, 2014.

9 Evans RA, Tian YC, Steadman R and Phillips AO: TGF-beta1mediated fibroblast-myofibroblast terminal differentiation-the role of Smad proteins. Exp Cell Res 282: 90-100, 2003.

10 Kakarla S, Song XT and Gottschalk S: Cancer-associated fibroblasts as targets for immunotherapy. Immunotherapy 4: 1129-1138, 2012.
11 Yokokura S, Kanaji N, Tadokoro A, Yokokura S, Kadowaki N and Bandoh S: Confluence-dependent resistance to cisplatin in lung cancer cells is regulated by transforming growth factorbeta. Exp Lung Res 42: 175-181, 2016.

12 Kanaji N, Sato T, Nelson A, Wang X, Li Y, Kim M, Nakanishi M, Basma H, Michalski J, Farid M, Chandler M, Pease W, Patil A, Rennard SI and Liu X: Inflammatory cytokines regulate endothelial cell survival and tissue repair functions via $\mathrm{NF}-\mathrm{kB}$ signaling. J Inflamm Res 4: 127-138, 2011.

13 Park AM, Hayakawa S, Honda E, Mine Y, Yoshida K and Munakata $\mathrm{H}$ : Conditioned media from lung cancer cell line A549 and PC9 inactivate pulmonary fibroblasts by regulating protein phosphorylation. Arch Biochem Biophys 518: 133-141, 2012.

Received January 18, 2018

Revised February 14, 2018

Accepted February 15, 2018 